\title{
Updated Oxford classification and the international study of kidney disease in children classification: application in predicting outcome of Henoch-Schönlein purpura nephritis
}

Xiaohan Huang 1,2,3,4, Lili Ma ${ }^{1,5}$, Pingping Ren 1,2,3,4 Hongya Wang ${ }^{1,2,3,4}$, Liangliang Chen ${ }^{1,2,3,4}$, Haidongqin Han ${ }^{1,2,3,4}$, Jianghua Chen ${ }^{1,2,3,4}$ and Fei Han ${ }^{1,2,3,4^{*}}$

\begin{abstract}
Background: Henoch-Schönlein purpura nephritis (HSPN) shares many similarities with IgA nephropathy. We aimed to analyze the predictive value of the International Study of Kidney Disease in Children (ISKDC) classification and the updated Oxford classification for IgA nephropathy in HSPN patients.

Methods: Data of 275 HSPN patients (aged $\geq 14$ years) were retrieved, and all of them underwent a renal biopsy. We re-classified the biopsies according to the ISKDC classification and the updated Oxford classification to analyze their correlations with clinical features and renal outcomes. The renal endpoints were defined as $\geq 30 \%$ reduction in baseline estimated glomerular filtration rate (eGFR) in 2 years, doubling of serum creatinine (Scr) or end stage renal disease.

Results: During follow-up period of 56(30,86) months, 30(10.9\%) patients reached renal endpoints. Segmental sclerosis was the only pathological feature independently associated with renal endpoints (HR 4.086, 95\% Cl 1.111$15.026, P=0.034)$. Tubular atrophy/ interstitial fibrosis was associated with eGFR and Scr levels, and its correlation with renal endpoints was found by univariate analysis. Endocapillary hypercellularity was associated with $24 \mathrm{~h}$ urine protein and is of prognostic value in univariate analysis. Mesangial hypercellularity was not associated with clinical features or renal endpoints. Crescents were associated with $24 \mathrm{~h}$ urine protein, Scr and eGFR levels, but both ISKDC and updated Oxford classifications of crescents were not associated with renal endpoints by multivariate analysis.
\end{abstract}

Conclusions: The updated Oxford classification can help in disease management and renal outcome prediction of HSPN.

Keywords: IgA vasculitis, Nephritis, Renal biopsy, Crescent, Outcomes

\footnotetext{
* Correspondence: hanf8876@zju.edu.cn

${ }^{1}$ Kidney Disease Center, The First Affiliated Hospital, College of Medicine,

Zhejiang University, 79 Qingchun Road, Hangzhou, Zhejiang Province

310003, People's Republic of China

${ }^{2}$ Institute of Nephrology, Zhejiang University, Hangzhou, Zhejiang Province,

China

Full list of author information is available at the end of the article
}

(c) The Author(s). 2019 Open Access This article is distributed under the terms of the Creative Commons Attribution 4.0 International License (http://creativecommons.org/licenses/by/4.0/), which permits unrestricted use, distribution, and reproduction in any medium, provided you give appropriate credit to the original author(s) and the source, provide a link to the Creative Commons license, and indicate if changes were made. The Creative Commons Public Domain Dedication waiver (http://creativecommons.org/publicdomain/zero/1.0/) applies to the data made available in this article, unless otherwise stated. 


\section{Background}

Henoch-Schönlein purpura (HSP), which also known as IgA vasculitis (IgAV), is an immunoglobulin A (IgA)-mediated disease characterized by a generalized vasculitis mainly involving the skin, joints, gastrointestinal tract and kidneys [1]. IgAV nephritis (IgAVN) or Henoch-Schönlein purpura nephritis (HSPN) is the kidney damage caused by IgAV. It has been reported that $7-23 \%$ of children and $10-27 \%$ of adults with HSPN would progress to end stage renal disease (ESRD) [2-5]. For HSP patients, a major factor affecting the long-term outcome is the severity of renal involvement [6], and it has been suggested that some pathologic features may have values in predicting the outcomes of HSPN [7].

Pathologic features of HSPN is usually graded by the International Study of Kidney Disease in Children (ISKDC) classification, mainly according to the existence and the number of crescents [8]. However, the value of crescents in predicting long-term outcome of HSPN is still lack of consensus. IgA nephropathy shares many similarities with HSPN in clinical, immunological and histological features [9]. In some studies, IgA nephropathy and HSPN were regarded as different manifestations of a single disease $[10,11]$. Therefore, the Oxford classification of IgA nephropathy may also be used to group pathologic features of HSPN. The updated Oxford classification uses mesangial hypercellularity $(\mathrm{M})$, endocapillary hypercellularity $(E)$, segmental sclerosis $(S)$, tubular atrophy/ interstitial fibrosis $(\mathrm{T})$ and crescents $(\mathrm{C})$ to evaluate renal biopsies [12]. A study published in 2014 suggested that the original Oxford classification was of prognostic value in HSPN [13], while another study in 2018 suggested that updated oxford classification can be used to assess renal outcomes of HSPN in children [14]. Here, we evaluated the utility of both the ISKDC classification and the updated Oxford classification as a predictor of renal outcome by retrospectively reviewing a larger cohort (275 patients, aged $\geq 14$ years)followed up in our center.

\section{Methods}

\section{Patients}

Data of 292 HSPN patients diagnosed by the Kidney Disease Center of the First Affiliated Hospital of Zhejiang University between August 2004 and November 2015 were retrieved. Criteria for a renal biopsy was HSPN patients who had active urinary sediments (proteinuria or hematuria) with or without impairment of glomerular filtration rate. Inclusive criteria included: aged $\geq 14$ years; a history of palpable purpuric eruption, with or without involvement of gastrointestinal tract or joints; biopsy-proven HSPN. Exclusion criteria was as follows: inadequate number of glomeruli $(<8)$ in biopsy, concomitant with cirrhotic liver disease, IgA-dominant infection associated glomerulonephritis, human immunodeficiency virus associated IgA nephropathy, anti-neutrophil cytoplasmic antibody associated vasculitis, hepatitis B virus associated nephritis, idiopathic thrombocytopenic purpura, systemic lupus erythematosus and other autoimmune diseases. Levels of antinuclear antibody (ANA), anti-neutrophil cytoplasmic antibody (ANCA), anti-glomerular basement antibody together with complements were collected to exclude autoimmune disease.

Of these 292 patients, 11 patients were lost to follow-up, and another 6 patients were excluded because of biopsy inadequacy $(<8$ glomeruli), the remaining 275 patients were the basis of our study. The study protocols conformed to the provisions of the Declaration of Helsinki. The Research Ethics Committee of the First Affiliated Hospital, College of Medicine, Zhejiang University approved the protocols (Reference number: 2017678).

\section{Clinical data collection}

Medical records of the patients were reviewed to obtain clinical data at the time of biopsy and during the course of follow-up. The data included age, gender, blood pressure, urine protein excretion based on 24-h urine collection, serum creatinine $(\mathrm{Scr})$ and estimated glomerular filtration rate (eGFR). Also, the use of immunosuppressant drugs was assessed. The mean arterial pressure (MAP) was calculated by the equation $\mathrm{MAP}=(2 \times$ diastolic pressure + systolic pressure)/3, while the eGFR was calculated using the Chronic Kidney Disease Epidemiology Collaboration (CKD-EPI) formula.

\section{Pathologic data collection}

Renal biopsy of all patients were graded according to the International Study of Kidney Disease in Children classification [8]: (I) minimal glomerular alterations; (II) mesangial proliferation; (IIIa) focal or (IIIb) diffuse proliferation or sclerosis with $<50 \%$ crescents; (IV) mesangial proliferation or sclerosis with $50-75 \%$ crescents; (V) mesangial proliferation or sclerosis with $>75 \%$ crescents; (VI) membranoproliferative-like lesion. Patients were divided into three groups: Group ISKDC-G0 included ISKDC grade I and II, Group ISKDC-G1 included ISKDC grade III, and ISKDC-G2 included ISKDC grade IV, V and VI. Pathologic findings in these renal biopsies were then re-evaluated with the updated Oxford classification MEST-C scoring system [12]:(1) mesangial proliferation $(\mathrm{M})$ : mesangial score $<0.5(\mathrm{M} 0)$, or $>0.5(\mathrm{M} 1)$; (2) endocapillary hypercellularity (E): absent (E0) or present (E1); (3) segmental glomerulosclerosis (S): absent (S0) or present (S1); (4) tubular atrophy/ interstitial fibrosis (T): 0-25\% (T0), 25-50\% (T1), > 50\% (T2); (5)cellular/ fibrocellular crescents (C): absent (C0), $0-25 \%(\mathrm{C} 1), \geq 25 \%$ 
(C2). Group T1 and T2 were merged because there were only 2 patients scored T2. One experienced renal pathologist who was blinded to the case histories evaluated all renal pathology.

\section{Definitions}

The primary renal endpoint was defined as $\geq 30 \%$ reduction of eGFR from baseline in 2 years, doubling of Scr or ESRD. ESRD was defined by reaching an eGFR of $<15$ $\mathrm{ml} / \mathrm{min} / 1.72 \mathrm{~m}^{2}$ or requiring maintaining renal replacement therapy for more than 3 months.

\section{Statistical analysis}

Statistical analysis was performed by IBM SPSS 22.0 (IBM, Chicago, IL, USA). Normal distributed data were expressed as mean \pm standard deviation, and comparisons were tested by Student's t test. Non-normal distributed data were expressed as median(interquartile range), and compared by the Mann-Whitney U-test. Chi-square $\chi^{2}$ test, Fisher's exact test and non-parametric test were used to compare categorical variables. We used one-way ANOVA and $\mathrm{R} \times \mathrm{C}$ contingency table for comparison of three groups. Student-Newman-Keuls test was used to further compare between two groups. To evaluate the association between the classifications and renal endpoint, we used univariate analysis and multivariate Cox regression model, defining the day of renal biopsy as starting point, and the result was presented with hazard ratios (HR). $P<0.05$ was considered significant.

\section{Results}

\section{Demographic and clinical features}

The study sample comprised 275 HSPN patients. At the time of biopsy, their mean age was $33 \pm 17$ years, and $52.0 \%$ were male. All of the patients were the Han population. During a median follow-up of $56(30,86)$ months, $30(10.9 \%)$ patients reached renal endpoints including more than $30 \%$ decrease in baseline eGFR in 2 years (11 patients), doubling in Scr (7 patients) and ESRD (12 patients). Comparations between patients with or without renal endpoints were shown in Table 1. There were no significant differences in age and extrarenal manifestations, but patients reaching endpoints had a higher male proportion, higher average MAP $(100 \pm 9 \mathrm{mmHg}$ vs $94 \pm 11$ $\mathrm{mmHg}, \quad p=0.012)$, higher Scr level [103.0 (74.8217.8) $\mu \mathrm{mol} / \mathrm{L}$ vs $63.0(53.0,78.0) \mu \mathrm{mol} / \mathrm{L}, p<0.001]$ and lower eGFR level $\left[67.4(30.1,115.4) \mathrm{ml} / \mathrm{min} / 1.73 \mathrm{~m}^{2}\right.$ vs 121.2 $\left.(92.6,140.1) \mathrm{ml} / \mathrm{min} / 1.73 \mathrm{~m}^{2}, p<0.001\right]$, and more proteinuria $[2.7(1.0,5.0) \mathrm{g} / 24 \mathrm{~h}$ vs $1.12(0.6,2.7) \mathrm{g} / 24 \mathrm{~h}, p<$ 0.001]. Angiotensin converting enzyme inhibitor (ACEI) / angiotensin II receptor blocker (ARB) and immunosuppressants were prescribed in our patients. A percentage of $72.7 \%$ of patients received immunosuppressive therapy; the percentage was same in patients with or without renal endpoints. However, patients with endpoints received a higher proportion of steroids combining with intravenous cyclophosphamide or mycophenolate mofetil (18/24 vs $83 / 176, p=0.019$ ), probably correlating with a higher severity of the disease.

The detailed pathologic features (including the severity of mesangial proliferation, the proportion of glomeruli

Table 1 Clinical features for patients with or without renal endpoints

\begin{tabular}{|c|c|c|c|}
\hline \multirow[t]{2}{*}{ Clinical features } & \multicolumn{2}{|c|}{ Renal endpoints reached } & \multirow[t]{2}{*}{$P$ value } \\
\hline & Yes & No & \\
\hline Number of patients & 30 & 245 & \\
\hline Mean age (years) & $42 \pm 22$ & $33 \pm 16$ & 0.052 \\
\hline Gender (Male/Female) & $21 / 9$ & $122 / 123$ & 0.036 \\
\hline \multicolumn{4}{|l|}{ Extrarenal manifestation } \\
\hline Skin $(n, \%)$ & $30(100 \%)$ & $245(100 \%)$ & \\
\hline Gastrointestinal tract $(n, \%)$ & $4(13.3 \%)$ & $62(24.3 \%)$ & 0.147 \\
\hline Joints (n, \%) & $1(3.3 \%)$ & $45(18.4 \%)$ & 0.068 \\
\hline MAP (mmHg) & $100 \pm 9$ & $94 \pm 11$ & 0.012 \\
\hline $\operatorname{Scr}(\mu \mathrm{mol} / \mathrm{L})$ & $103.0(74.8217 .8)$ & $63.0(53.0,78.0)$ & $<0.001$ \\
\hline eGFR $\left(\mathrm{ml} / \mathrm{min} / 1.73 \mathrm{~m}^{2}\right)$ & $67.4(30.1,115.4)$ & $121.2(92.6,140.1)$ & $<0.001$ \\
\hline Proteinuria(g/24 h) & $2.7(1.0,5.0)$ & $1.12(0.6,2.7)$ & $<0.001$ \\
\hline Immunosuppressant therapy (n, \%) & $24(80.0 \%)$ & $176(71.8 \%)$ & 0.343 \\
\hline Steroids only(n) & 6 & 93 & 0.019 \\
\hline Steroids + IVC/MMF(n) & 18 & 83 & \\
\hline ACEI/ARB & $12(40.0 \%)$ & $83(33.9 \%)$ & 0.51 \\
\hline
\end{tabular}

The data were expressed as mean \pm s.d. or as numbers(percentage)

Results of Scr, eGFR, proteinuria were expressed as median (interquartile range)

$M A P$ mean arterial pressure, $S c r$ serum creatinine, eGFR estimated glomerular filtration rate, IVC intravenous cyclophosphamide, MMF mycophenolate mofetil, ACEI angiotensin converting enzyme inhibitor, $A R B$ angiotensin II receptor blocker 
with each pathologic lesion, and the proportion of interstitial inflammation) in patients with or without renal endpoints were shown in Table 2. A greater proportion of glomeruli with crescents $(p<0.001)$, and higher percentages of tubular atrophy $(p=0.013)$ and tubulointerstitial inflammation $(P=0.004)$ were observed in patients reaching renal endpoints. Immunofluorescence deposition feature is provided in Additiobnal file 1: Table S1

Distribution of the patients categorized by the ISKDC classification and the updated Oxford classification was presented in Table 3. There were 101(36.7\%) patients graded ISKDC II, 148(53.8\%) patients graded IIIa, 17(6.2\%) patients graded IIIb, $8(2.9 \%)$ patients graded IV, and only $1(0.4 \%)$ patients graded V. No patient was graded I or VI. By the updated Oxford classification, M1, E1, S1, T1/T2 were observed in $41(14.9 \%), 82(29.8 \%), 149(54.2 \%), 8(2.9 \%)$ patients respectively. Additionally, there were only 6 patients graded T1, and 2 patients graded T2, so we merged them in a group (T1/T2) for analysis. With regards to crescents, 141(51.3\%) patients scored $\mathrm{C} 1$ and 35(12.7\%) patients scored C2. For renal outcomes, the percentage of patients reaching renal endpoints increased with the increasing grade from ISKDC-G0, G1 to G2 (4.9, 12.7, 44.4\% respectively, $p<0.001$ ), and those in M1, E1, S1, T1/T2, C1 or C2 groups of the updated Oxford classification were 12.1, 15.8, $12.7,25,13.4 \%$ or $20 \%$, respectively.

\section{Correlations between clinical data and pathologic classifications}

Correlations between clinical data and pathologic classifications were shown in Table 4. According to the ISKDC classification, with the increase of classification from ISKDC G0, G1 to G2, patients had more daily urine protein $(p<0.05)$, higher Scr level $(p<$ $0.05)$ and lower eGFR level $(p<0.05)$. According to the updated Oxford classification, no significant difference in MAP, proteinuria, eGFR and Scr levels was found between M0 and M1 group; patients in E1 group had more daily urine protein than E0 group ( $p$ $<0.001)$; patients in S1 group had higher MAP level $(p=0.003)$, higher Scr level $(p<0.001)$ and lower eGFR level $(\mathrm{p}<0.001)$ than those in S0 group; patients in T1/T2 group had higher Scr level $(p=0.001)$ and lower eGFR level $(\mathrm{p}=0.001)$ than those in T0 group; both patients in $\mathrm{C} 1$ group (Crescents $0-25 \%$ ) and $\mathrm{C} 2$ group (Crescents $\geq 25 \%$ ) had more daily urine protein $(p<0.05)$, higher Scr level $(p<0.05)$ and lower eGFR level $(p<0.05)$ than those in C0 group; furthermore, patients in $\mathrm{C} 2$ group have more proteinuria than $\mathrm{C} 1$ group.

\section{Correlations between outcomes and pathologic classifications}

Survival analysis was shown in Table 5 . By the univariate Cox regression analysis, $\mathrm{E} 1(P=0.038), \mathrm{S} 1(p=0.005), \mathrm{T} 1 /$ $\mathrm{T} 2(\mathrm{p}<0.001)$ and $\mathrm{C} 1 / \mathrm{C} 2(\mathrm{p}=0.005)$ were risk factors for renal endpoints. In multivariate model, variants including age, 24-h proteinuria, eGFR, and pathologic features (E1, S1, T1/T2 and C1/C2) were analyzed; and S1 lesion $(\mathrm{HR}=4.08695 \% \mathrm{CI}=1.111-15.026, p=0.034)$ and more proteinuria $(\mathrm{HR}=1.191,95 \% \mathrm{CI}=1.012-1.401, p=0.035)$ were independently risk factors for renal endpoints.

Table 2 Detailed pathologic features for patients with or without renal endpoints

\begin{tabular}{|c|c|c|c|}
\hline \multirow[t]{2}{*}{ Pathologic features } & \multicolumn{2}{|c|}{ Renal endpoints reached } & \multirow[t]{2}{*}{$P$ value } \\
\hline & Yes & No & \\
\hline Mesangial hypercellularity ${ }^{\mathrm{a}}, \mathrm{n}(\%)$ & & & 0.238 \\
\hline Normal & 0 & $2(0.4)$ & \\
\hline Mild & $26(86.7)$ & $207(84.5)$ & \\
\hline Moderate & $3(10.0)$ & $35(14.3)$ & \\
\hline Severe & $1(3.3)$ & $1(0.4)$ & \\
\hline tubulointerstitial inflammation ${ }^{\mathrm{a}, \mathrm{b}}, \mathrm{n}(\%)$ & & & 0.004 \\
\hline Absent & $4(13.3)$ & $68(27.7)$ & \\
\hline$\leq 25 \%$ & $12(40.0)$ & $133(54.3)$ & \\
\hline$>25 \%$ and $\leq 50 \%$ & $6(20.0)$ & $12(4.9)$ & \\
\hline$>50 \%$ & $8(26.7)$ & $32(13.1)$ & \\
\hline \multicolumn{4}{|l|}{ Proportion of glomeruli per biopsy } \\
\hline Segmental sclerosis (\%) ${ }^{c}$ & $3.4(0,16.7)$ & $2.0(0,7.5)$ & 0.098 \\
\hline Crescents $(\%)^{c}$ & $12.9(3.5,23.3)$ & $4.0(0,13.3)$ & $<0.001$ \\
\hline Tubular atrophy $(\%)^{c}$ & $5(1,15)$ & $5(0,5)$ & 0.013 \\
\hline
\end{tabular}


Table 3 Distribution of patients classified according to the updated Oxford classification or the International Study of Kidney Disease in Children classification

\begin{tabular}{|c|c|c|c|}
\hline Classification & All patients ${ }^{a}$ & Patients reaching endpoints ${ }^{b}$ & $P$ value \\
\hline \multicolumn{4}{|c|}{ International Study of Kidney Disease in Children classification } \\
\hline । & 0 & 0 & \\
\hline$\|$ & $101(36.7 \%)$ & $5(4.9 \%)$ & \\
\hline Illa & $148(53.8 \%)$ & $18(12.2 \%)$ & \\
\hline$\| l l b$ & $17(6.2 \%)$ & $3(17.6 \%)$ & \\
\hline IV & $8(2.9 \%)$ & $3(37.5 \%)$ & \\
\hline V & $1(0.4 \%)$ & $1(100 \%)$ & \\
\hline $\mathrm{Vl}$ & 0 & 0 & \\
\hline ISKDC-G0 & $101(36.7 \%)$ & $5(4.9 \%)$ & $<0.001$ \\
\hline ISKDC-G1 & $165(60.0 \%)$ & $21(12.7 \%)$ & \\
\hline ISKDC-G2 & $9(3.3 \%)$ & $4(44.4 \%)$ & \\
\hline \multicolumn{4}{|c|}{ Updated Oxford classification } \\
\hline MO & $234(85.1 \%)$ & 25 (10.6\%) & 0.775 \\
\hline M1 & 41 (14.9\%) & 5 (12.1\%) & \\
\hline EO & $193(70.2 \%)$ & 17 (8.8\%) & 0.086 \\
\hline E1 & 82 (29.8\%) & $13(15.8 \%)$ & \\
\hline so & $126(45.8 \%)$ & 11 (8.7\%) & 0.287 \\
\hline S1 & 149 (54.2\%) & 19 (12.7\%) & \\
\hline T0 & 267 (97.1\%) & $28(10.4 \%)$ & 0.194 \\
\hline $\mathrm{T} 1 / \mathrm{T} 2$ & 8 (2.9\%) & 2 (25.0\%) & \\
\hline $\mathrm{CO}$ & 99 (36.0\%) & $4(4.0 \%)$ & $0.011^{c}$ \\
\hline C1 & $141(51.3 \%)$ & 19 (13.4\%) & $0.386^{d}$ \\
\hline C2 & 35 (12.7\%) & 7 (20.0\%) & \\
\hline
\end{tabular}

Data was expressed as numbers(percentages)

${ }^{a}$ Number of patients in the group, and the proportion in all patients

${ }^{b}$ Number of patients reached endpoint and the proportion in this group

${ }^{\mathrm{C}} \mathrm{C} 0$ compares to $\mathrm{C} 1+\mathrm{C} 2$, crescent absent vs crescent formation

${ }^{\mathrm{d}} \mathrm{CO}, \mathrm{C} 1, \mathrm{C} 2$, comparison made by contingency table

\section{Discussion}

We showed that the $\mathrm{S}$ lesion was an independent risk factor for poor renal outcome in HSPN. This was in agreement with previous studies in $\operatorname{HSPN}[3,14]$ and IgA nephropathy including the oxford cohort [15-18]. The $\mathrm{S}$ lesion is considered to represent chronic and late stage kidney damage; therefore, the presence of $\mathrm{S}$ lesion can be valuable in predicting renal outcome of HSPN.

Tubular and interstitial lesions were not mentioned in ISKDC classification but were regarded as independent risk factors of IgA nephropathy according to the Oxford classification [12], validated by following studies [1820]. The $\mathrm{T}$ lesions were related to higher Scr level and lower eGFR level, but not proven to be an independent risk factor of poor renal outcome in the present study. The degree of tubulointerstitial inflammation was associated with poor outcome, and by univariate Cox analysis, tubular atrophy and interstitial fibrosis were associated with poor renal prognosis, but Cox multivariate regression analysis failed to demonstrate the correlation. This result agreed with the study of Inagaki et al [21]. However, we must mention that the inadequacy of sample (only 8 patients were categorized in T1/T2 group) may mask the prognostic value of the $\mathrm{T}$ lesions. In the study of Kim et al [13] tubular atrophy and interstitial fibrosis were suggested to be an independent risk factor, but the number of cases in their study was also limited (8 patients). This may indicate that T1 or T2 lesion were relatively rare in HSPN patients.

In our study, mesangial proliferation was not related with renal outcome. This is consistent with previous studies, including a new classification for predicting outcomes of HSPN raised by Mikael K et al [22]. Thus, although the $\mathrm{M}$ lesion was confirmed to be a significant predicting factor in IgA nephropathy, its value in HSPN is still lack of evidence.

Patients presented with endocapillary hypercellularity had larger amount of $24 \mathrm{~h}$ urine protein excretion. The degree of proteinuria is proved to be a significant prognostic factor in our study and studies reported [3, 8, 23]. And, the E lesion was found of prognostic value in univariate cox model in our study. Glomerular endothelial cells are important components of the renal filtration barrier and the E lesion can damage the filtration barrier, letting protein leak into the urine, thus increase urine protein excretion. At the same time, the E lesion is considered to be an acute lesion related with inflammation, which can be reversed by immunosuppressant drugs or steroid therapy, so its chronic effect on GFR may be limited [24], and its correlation with renal outcome is still unclear. Our study, which found the E lesion was not independently associated with outcome, is consistent with the oxford classification study [16] and the VALIGA cohort [25] of IgA nephropathy. But it is in the contrary to studies with smaller patient population from Korea and Japan $[13,21]$. Some studies had suggested that immunosuppressive therapy might affect the prognostic value of the E lesion in IgA nephropathy [26-28], so the high proportion of immunosuppressive therapy in our study may improve the effect of $E$ lesion on renal outcome.

Crescents were also associated with more daily urine protein excretion, higher Scr and lower eGFR, supporting that the number of crescents was related with severity of clinical manifestation of $\operatorname{HSPN}[2,29,30]$. The utility of crescents as a predictor of renal outcome in HSPN was long-debated. The formation of crescents has been a main grading parameter in the ISKDC classification since 1977; however, its correlation with renal outcome was not clear. Crescents were related with poor prognosis in some studies [2, 30, 31], but it was not confirmed by others $[3,13,23]$. Similar situation occurs in 
Table 4 Correlations between clinical data and pathologic classifications by the updated Oxford classification or the International Study of Kidney Disease in Children classification

\begin{tabular}{|c|c|c|c|c|c|c|c|c|}
\hline & MAP, mmHg & $P$ value & Proteinuria, $g / 24 \mathrm{~h}$ & $P$ value & $\mathrm{eGFR}, \mathrm{ml} / \mathrm{min} / 1.73 \mathrm{~m}^{2}$ & $P$ value & $\mathrm{Scr}, \mu \mathrm{mol} / \mathrm{L}$ & $P$ value \\
\hline \multicolumn{9}{|c|}{ International Study of Kidney Disease in Children classification } \\
\hline ISKDC-G0 & $93.8 \pm 10.7$ & & $0.75(0.40,1.75)$ & & $123.8(96.0,145.4)$ & & $60.0(50.5,75.0)$ & \\
\hline ISKDC-G1 & $95.9 \pm 10.6$ & & $1.50(0.75,3.00)^{\mathrm{a}}$ & & $111.4(81.4,134.6)^{\mathrm{a}}$ & & $68.0(55.0,91.5)^{\mathrm{a}}$ & \\
\hline ISKDC-G2 & $95.0 \pm 10.5$ & & $3.60(2.00,5.50)^{\mathrm{ab}}$ & & $30.7(24.5,138.6)^{\mathrm{ab}}$ & & $150.0(56.0,244.5)^{\mathrm{ab}}$ & \\
\hline \multicolumn{9}{|c|}{ Updated Oxford classification } \\
\hline \multicolumn{9}{|c|}{ Messangial proliferation } \\
\hline MO & $95.1 \pm 10.4$ & 0.303 & $1.23(0.60,3.00)$ & 0.859 & $116.2(87.6,139.6)$ & 0.429 & $65.0(53.0,81.3)$ & 0.098 \\
\hline M1 & $94.3 \pm 12.4$ & & $1.34(0.73,3.01)$ & & $107.3(85.5,134.7)$ & & $72.0(56.0,92.0)$ & \\
\hline \multicolumn{9}{|c|}{ Endocapillary proliferation } \\
\hline E0 & $94.5 \pm 10.3$ & 0.160 & $1.00(0.46,2.15)$ & $<0.001$ & $118.6(89.7,136.3)$ & 0.798 & $65.0(54.0,84.0)$ & 0.946 \\
\hline E1 & $96.2 \pm 11.4$ & & $2.02(1.00,3.44)$ & & $110.4(80.5,145.3)$ & & $66.0(52.0,84.3)$ & \\
\hline \multicolumn{9}{|c|}{ Segmental sclerosis } \\
\hline so & $91.5 \pm 10.2$ & 0.003 & $1.06(0.52,3.00)$ & 0.423 & $130.4(109.3,144.9)$ & $<0.001$ & $60.3(51.0,75.0)$ & $<0.001$ \\
\hline S1 & $96.8 \pm 10.8$ & & $1.50(0.70,3.00)$ & & $99.0(75.2,125.1)$ & & $68.5(59.3,94.0)$ & \\
\hline \multicolumn{9}{|c|}{ Tubular atrophy/ interstitial fibrosis } \\
\hline T0 & $94.9 \pm 10.7$ & 0.148 & $1.30(0.64,3.00)$ & 0.273 & $118.9(89.8,139.4)$ & 0.001 & $65.0(54.0,81.0)$ & 0.001 \\
\hline $\mathrm{T} 1 / \mathrm{T} 2$ & $99.4 \pm 7.1$ & & $2.72(1.00,3.43)$ & & $45.3(18.4,76.7)$ & & $138.5(106.8,276.0)$ & \\
\hline \multicolumn{9}{|l|}{ Crescents } \\
\hline $\mathrm{CO}$ & $93.6 \pm 10.7$ & & $0.75(0.42,1.97)$ & & $124.2(96.5,145.6)$ & & $59.1(50.7,74.0)$ & \\
\hline $\mathrm{C} 1$ & $95.9 \pm 11.0$ & & $1.50(0.75,3.05)^{c}$ & & $114.8(81.9,134.8)^{c}$ & & $70.2(54.0,89.0)^{c}$ & \\
\hline C2 & $95.1 \pm 8.8$ & & $2.49(1.33,4.65)^{\mathrm{cd}}$ & & $95.9(41.9,131.9)^{c}$ & & $68.6(57.0,150.5)^{c}$ & \\
\hline
\end{tabular}

MAP, mean arterial pressure; Scr, serum creatinine; eGFR, estimated glomerular filtration rate; ISKDC, International Study of Kidney Disease in Children. ${ }^{\text {a }} P<0.05$ compared with ISKDC-G0, ${ }^{b} P<0.05$ compared with ISKDC-G1; ${ }^{c} P<0.05$ compared with $\mathrm{C} 0,{ }^{d} P<0.05$ compared with C1

Results of MAP were provided in mean \pm standard deviation while results of Scr, eGFR, proteinuria were provided in median and (interquartile range)

IgA nephropathy [32-34]. Crescents were relatively rare in IgA patients and were not used as a parameter in the Oxford classification until its recent update. The researchers also pointed out that only in those who did not receive immunosuppression was the association between crescents and poor prognosis statistically significant [12]. In our study, crescents graded by both the
ISKDC and the Oxford classification was not independently related with renal outcome, probably correlating with the high proportion of immunosuppressive therapy (72.7\%).

Our study shared some similarities with those done by Kim et al [13] and Xu et al [14]. In Kim's study, E lesion and $\mathrm{T}$ lesions were suggested to be of prognostic value,

Table 5 Cox model analysis for renal endpoints

\begin{tabular}{|c|c|c|c|c|c|c|}
\hline \multirow[t]{2}{*}{ Factors } & \multicolumn{3}{|c|}{ univariate } & \multicolumn{3}{|c|}{ Multivariate $^{a}$} \\
\hline & $\mathrm{HR}$ & $95 \% \mathrm{Cl}$ & $P$ value & $\mathrm{HR}$ & $95 \% \mathrm{Cl}$ & $P$ value \\
\hline ISKDC G1/G2 & 2.359 & $0.868-6.411$ & 0.092 & - & - & - \\
\hline M1 & 0.979 & $0.326-3.873$ & 0.854 & - & - & - \\
\hline E1 & 2.447 & $1.051-5.697$ & 0.038 & 1.527 & $0.571-4.082$ & 0.399 \\
\hline S1 & 3.597 & $1.196-10.717$ & 0.023 & 4.086 & $1.111-15.026$ & 0.034 \\
\hline $\mathrm{T} 1 / \mathrm{T} 2$ & 9.834 & $2.749-35.173$ & $<0.001$ & 2.605 & $0.546-12.434$ & 0.230 \\
\hline $\mathrm{C} 1 / \mathrm{C} 2$ & 2.387 & $1.296-4.394$ & 0.005 & 1.757 & $0.858-3.598$ & 0.123 \\
\hline Age & 1.030 & $1.007-1.054$ & 0.010 & 1.007 & $0.981-1.034$ & 0.590 \\
\hline Proteinuria & 1.196 & $1.059-1.351$ & 0.004 & 1.191 & $1.012-1.401$ & 0.035 \\
\hline eGFR & 0.979 & $0.969-0.991$ & $<0.001$ & 0.993 & $0.980-1.006$ & 0.284 \\
\hline
\end{tabular}

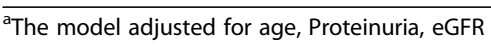


while in Xu's study, $\mathrm{S}$ and $\mathrm{T}$ lesions were of clinical value in outcome prediction. Possible factors which may lead to the difference were mentioned in previous paragraphs. Additionally, the disparity of patient population, follow-up duration and classification may also lead to the difference. Our study included a larger cohort (273 patients vs 92 patients or 104 patients respectively) and had longer median follow-up duration (56.0 months vs 49.3 months or 40 months respectively). Patients in our study were 14 years old or older (characteristics and survival curve of different age groups were provieded in Additional file 2: Table S2 and Additional file 3: Figure S1), while in Kim's study the inclusive criteria was aged $\geq 16$ years, and Xu's study focused on pediatric patients. Also, we used updated Oxford classification instead of the original one, and evaluated the value of ISKDC classification as well.

There were several limitations in our study. Despite many similarities shared by HSPN and IgA nephropathy, there are still differences existing between them. Diffused endocapillary hypercellularity and crescents for example, are observed more common in HSPN than IgA nephropathy [9]. Besides, as a single-center retrospective study, selection bias was unavoidable. Also, the median follow-up duration of was 56 months, which was relatively shorter to observe more endpoint events. And the inadequacy of patient number, especially patients with $\mathrm{T} 1$ or T2 lesions, may restrict the accuracy of our study.

\section{Conclusion}

The Oxford classification, especially the $\mathrm{S}$ score was helpful to evaluate the renal outcome of HSPN and can be used in disease management together with ISKDC classification.

\section{Additional files}

\section{Additional file 1: Table S1. Clinical and pathological features of} patients in different age group. (DOCX $17 \mathrm{~kb}$ )

Additional file 2: Table S2. Immunofluorescence deposition characteristics. (DOCX $15 \mathrm{~kb}$ )

Additional file 3: Figure S1. K-M curve of different age groups. (DOCX $31 \mathrm{~kb}$ )

\footnotetext{
Abbreviations

ANA: antinuclear antibody; ANCA: anti-neutrophil cytoplasmic antibody; eGFR: estimated glomerular filtration rate; ESRD: End stage renal disease; HSP: Henoch-Schönlein purpura; HSPN: Henoch-Schönlein purpura nephritis; IgA: Immunoglobin A; IgAV: IgA vasculitis; IgAVN: IgA vasculitis nephritis; ISKDC: International Study of Kidney Disease in Children; MAP: mean arterial pressure; Scr: serum creatinine
}

\section{Acknowledgments}

Not applicable

\section{Funding}

This study was supported by the funds from National Natural Science Foundation of China $(81570605,81770674)$ to Fei Han.
Availability of data and materials

The datasets used and/or analysed during the current study are available from the corresponding author on reasonable request.

\section{Authors' contributions}

All of the authors listed have made substantial contributions to the paper. $\mathrm{XH}$ and LM designed the research, conducted analysis and interpretation of data; PR, HW, LC, and HH has contributed to acquisition of data and assisted data analysis; FH drafted the research concept and revised the article critically with JC. All authors read and approved the final manuscript.

\section{Ethics approval and consent to participate}

The Research Ethics Committee of the First Affiliated Hospital, College of Medicine, Zhejiang University approved the protocols (Reference number: 2017678). Due to the retrospective nature of the study, informed consent was waived

\section{Consent for publication}

Not applicable.

\section{Competing interests}

The authors declare that they have no competing interests.

\section{Publisher's Note}

Springer Nature remains neutral with regard to jurisdictional claims in published maps and institutional affiliations.

\section{Author details}

${ }^{1}$ Kidney Disease Center, The First Affiliated Hospital, College of Medicine, Zhejiang University, 79 Qingchun Road, Hangzhou, Zhejiang Province 310003, People's Republic of China. ${ }^{2}$ Institute of Nephrology, Zhejiang University, Hangzhou, Zhejiang Province, China. ${ }^{3}$ Key Laboratory of Kidney Disease Prevention and Control Technology, Hangzhou, Zhejiang Province, China. ${ }^{4}$ The Third Grade Laboratory under the National State Administration of Traditional Chinese Medicine, Hangzhou, China. ${ }^{5}$ Department of Nephrology, Shaoxing Traditional Chinese Medicine Hospital, Shaoxing, China.

Received: 25 January 2019 Accepted: 25 April 2019 Published online: 10 May 2019

\section{References}

1. D'Amico G. Natural history of idiopathic IgA nephropathy and factors predictive of disease outcome. Semin Nephrol. 2004;24:179-96.

2. Shrestha S, Sumingan N, Tan J, Alhous H, McWilliam L, Ballardie F. Henoch Schonlein purpura with nephritis in adults: adverse prognostic indicators in a UK population. QJM. 2006:99:253-65.

3. Pillebout E, Thervet E, Hill G, Alberti C, Vanhille P, Nochy D. HenochSchonlein Purpura in adults: outcome and prognostic factors. J Am Soc Nephrol. 2002;13:1271-8

4. Coppo R, Mazzucco G, Cagnoli L, Lupo A, Schena FP. Long-term prognosis of Henoch-Schonlein nephritis in adults and children. Italian Group of Renal Immunopathology Collaborative Study on Henoch-Schonlein purpura. Nephrol Dial Transplant. 1997;12:2277-83.

5. Butani L, Morgenstern BZ. Long-term outcome in children after HenochSchonlein purpura nephritis. Clin Pediatr (Phila). 2007;46:505-11.

6. Lau KK, Suzuki H, Novak J, Wyatt RJ. Pathogenesis of Henoch-Schonlein purpura nephritis. Pediatr Nephrol. 2010;25:19-26.

7. Davin JC. Henoch-Schonlein purpura nephritis: pathophysiology, treatment, and future strategy. Clin J Am Soc Nephrol. 2011;6:679-89.

8. Counahan R, Winterborn MH, White RH, Heaton JM, Meadow SR, Bluett NH, et al. Prognosis of Henoch-Schonlein nephritis in children. Br Med J. 1977;2:11-4.

9. Davin JC, ten Berge $\mathrm{JJ}$, Weening JJ. What is the difference between IgA nephropathy and Henoch-Schonlein purpura nephritis? Kidney Int. 2001;59: 823-34

10. Oh HJ, Ahn SV, Yoo DE, Kim SJ, Shin DH, Lee MJ, et al. Clinical outcomes, when matched at presentation, do not vary between adult-onset Henoch-Schonlein purpura nephritis and IgA nephropathy. Kidney Int. 2012;82:1304-12.

11. Waldo FB. Is Henoch-Schonlein purpura the systemic form of IgA nephropathy? Am J Kidney Dis. 1988;12:373-7. 
12. Trimarchi H, Barratt J, Cattran DC, Cook HT, Coppo R, Haas M, et al. Oxford classification of IgA nephropathy 2016: an update from the IgA nephropathy classification working group. Kidney Int. 2017;91:1014-21.

13. Kim CH, Lim BJ, Bae YS, Kwon YE, Kim YL, Nam KH, et al. Using the Oxford classification of IgA nephropathy to predict long-term outcomes of Henoch-Schonlein purpura nephritis in adults. Mod Pathol. 2014;27:972-82.

14. Xu K, Zhang L, Ding J, Wang S, Su B, Xiao H, et al. Value of the Oxford classification of IgA nephropathy in children with Henoch-Schönlein purpura nephritis. Journal of Nephrology. 2018;31:279-86.

15. Shi SF, Wang SX, Jiang L, LV JC, Liu LJ, Chen YQ, et al. Pathologic predictors of renal outcome and therapeutic efficacy in IgA nephropathy: validation of the oxford classification. Clin J Am Soc Nephrol. 2011;6:2175-84.

16. Working Group of the International Ig ANN, The renal pathology S, Cattran DC, Coppo R, Cook HT, Feehally J, et al. The Oxford classification of IgA nephropathy: rationale, clinicopathological correlations, and classification. Kidney Int. 2009;76:534-45.

17. Tanaka S, Ninomiya T, Katafuchi R, Masutani $K$, Tsuchimoto A, Noguchi $H$, et al. Development and validation of a prediction rule using the Oxford classification in IgA nephropathy. Clin J Am Soc Nephrol. 2013;8:2082-90.

18. Herzenberg AM, Fogo AB, Reich HN, Troyanov S, Bavbek N, Massat AE, et al. Validation of the Oxford classification of IgA nephropathy. Kidney Int. 2011; 80:310-7.

19. Alamartine E, Sauron C, Laurent B, Sury A, Seffert A, Mariat C. The use of the Oxford classification of IgA nephropathy to predict renal survival. Clin J Am Soc Nephrol. 2011;6:2384-8.

20. Katafuchi R, Ninomiya T, Nagata M, Mitsuiki K, Hirakata H. Validation study of oxford classification of IgA nephropathy: the significance of extracapillary proliferation. Clin J Am Soc Nephrol. 2011;6:2806-13.

21. Inagaki K, Kaihan AB, Hachiya A, Ozeki T, Ando M, Kato S, et al. Clinical impact of endocapillary proliferation according to the Oxford classification among adults with Henoch-Schonlein purpura nephritis: a multicenter retrospective cohort study. BMC Nephrol. 2018;19:208.

22. Koskela M, Ylinen E, Ukonmaanaho EM, Autio-Harmainen H, Heikkila P, Lohi $J$, et al. The ISKDC classification and a new semiquantitative classification for predicting outcomes of Henoch-Schonlein purpura nephritis. Pediatr Nephrol. 2017;32:1201-9.

23. Coppo R, Andrulli S, Amore A, Gianoglio B, Conti G, Peruzzi L, et al. Predictors of outcome in Henoch-Schonlein nephritis in children and adults. Am J Kidney Dis. 2006;47:993-1003.

24. Hotta O, Furuta T, Chiba S, Tomioka S, Taguma Y. Regression of IgA nephropathy: a repeat biopsy study. Am J Kidney Dis. 2002;39:493-502.

25. Coppo R, Troyanov S, Bellur S, Cattran D, Cook HT, Feehally J, et al. Validation of the Oxford classification of IgA nephropathy in cohorts with different presentations and treatments. Kidney Int. 2014;86:828-36.

26. El Karoui K, Hill GS, Karras A, Jacquot C, Moulonguet L, Kourilsky O, et al. A clinicopathologic study of thrombotic microangiopathy in lgA nephropathy. J Am Soc Nephrol. 2012;23:137-48.

27. Chakera A, MacEwen C, Bellur SS, Chompuk LO, Lunn D, Roberts ISD. Prognostic value of endocapillary hypercellularity in IgA nephropathy patients with no immunosuppression. J Nephrol. 2016;29:367-75.

28. Shen XH, Liang SS, Chen HM, Le WB, Jiang S, Zeng CH, et al. Reversal of active glomerular lesions after immunosuppressive therapy in patients with IgA nephropathy: a repeat-biopsy based observation. J Nephrol. 2015;28: $441-9$.

29. Schillinger F, Denis PS, Dion JJ, Montagnac R, Melin JP, Milcent T, et al. Severe Schonlein-Henoch nephritis in adults. A report of twenty cases. Nephrologie. 2000;21:247-52

30. Szeto CC, Choi PC, To KF, Li PK, Hui J, Chow KM, et al. Grading of acute and chronic renal lesions in Henoch-Schonlein purpura. Mod Pathol. 2001;14: 635-40.

31. Goldstein AR, White RH, Akuse R, Chantler C. Long-term follow-up of childhood Henoch-Schonlein nephritis. Lancet. 1992;339:280-2.

32. Roberts IS. Oxford classification of immunoglobulin a nephropathy: an update. Curr Opin Nephrol Hypertens. 2013;22:281-6.

33. Lv J, Shi S, Xu D, Zhang H, Troyanov S, Cattran DC, et al. Evaluation of the Oxford classification of IgA nephropathy: a systematic review and metaanalysis. Am J Kidney Dis. 2013;62:891-9.

34. Shima Y, Nakanishi K, Hama T, Mukaiyama H, Togawa H, Hashimura Y, et al. Validity of the Oxford classification of IgA nephropathy in children. Pediatr Nephrol. 2012;27:783-92.

Ready to submit your research? Choose BMC and benefit from:

- fast, convenient online submission

- thorough peer review by experienced researchers in your field

- rapid publication on acceptance

- support for research data, including large and complex data types

- gold Open Access which fosters wider collaboration and increased citations

- maximum visibility for your research: over $100 \mathrm{M}$ website views per year

At $\mathrm{BMC}$, research is always in progress.

Learn more biomedcentral.com/submissions 